\title{
Diabetikerversorgung in Gefahr?
}

\author{
Die neuen Straftatbestände der Bestechlichkeit bzw. Bestechung im \\ Gesundheitswesen hemmen die Versorgung von Diabetespatienten.
}

_ Seit Juni gelten die neuen Strafvorschriften der $\$ \$ 299 a$ und $299 b$ StGB. Angehörige der Heilberufe und der Industrie können sich nun der Bestechlichkeit und der Bestechung im Gesundheitswesen schuldig machen. Doch auch die Patienten werden die Auswirkungen des Gesetzes in der Praxis spüren.

So sind es Diabetespatienten gewohnt, dass sie vom Arzt kostenlos und ohne Rezept ein geeignetes Blutzuckermessgerät oder Insulin-Pens bekommen. Viele Firmen stellten den Praxen hierfür Geräte zur Verfügung. Seit Inkrafttreten des Gesetzes geben die meisten Anbieter aber keine Systeme mehr ab, da sie sich nicht dem Vorwurf einer Bestechung aussetzen wollen.

Ganz abwegig ist das nicht, handelt es sich hierbei doch um hochwertige Medizinprodukte mit erheblichem Warenwert. Es ist auch nicht gänzlich fernliegend, dass der Arzt womöglich bevorzugt passende Teststreifen bzw. Insulin für solche Geräte verordnet, die er seinen Patienten zuvor kostenlos abgeben konnte. Kleinere Hersteller, die sich das massenweise Verschenken solcher Produkte nicht leisten können, würden dann benachteiligt, obwohl sie vielleicht gleich hohe Qualität bei womöglich günstigeren Teststreifen- bzw. Insulinpreisen anbieten.

Als Arzt hat man dabei durchaus auch selbst Vorteile, erspart man sich doch den Aufwand und ggf. das Regressrisiko einer ansonsten notwendigen Verordnung. Auch kann man seinen Patienten einen besonderen „Service“ bieten.
Des Weiteren war es bisher üblich, dass an Praxen kostenlose Software zum Diabetes-Datenmanagement abgegeben wurde, sodass solche Programme nicht $\mathrm{zu}$ vierstelligen Beträgen auf dem freien Markt beschafft werden mussten. Auch die Fortbildung von Ärzten und Diabetesberaterinnen wurde bislang in großen Teilen von der Industrie (mit)getragen.

Die Angst vor einer Strafverfolgung dürfte dazu führen, dass solche Unterstützungen der ärztlichen Arbeit künftig deutlich zurückgeschraubt werden. Auch manche Ärzte werden in Zukunft sicherlich zweimal überlegen, ob sie kostenlose Angebote der Industrie annehmen - selbst wenn diese absolut unproblematisch sind.

\section{Neue Verbote gibt es nicht}

Generell ist zu beobachten, dass eine erhebliche Unsicherheit herrscht. Dies kann mittelfristig zu einer Verschlechterung der Versorgungslage führen, zumal eine Kompensation des bislang von der Industrie übernommenen Unterstützungsanteils an der diabetologischen Fortbildung bzw. Betreuung nicht in Sicht ist - eher im Gegenteil.

Bei aller berechtigter Kritik an der handwerklichen Ausführung des Gesetzes geht in der Diskussion allerdings häufig unter, dass die neuen Regelungen keine zusätzlichen Verbote schaffen. Zuwendungen an Ärzte waren angesichts einschlägiger Verbotsnormen, beispielsweise aus Standes- und Wettbewerbsrecht, dem Heilmittelwerbegesetz ( $\$ 7$ HWG) oder dem Sozialgesetzbuch (ins-

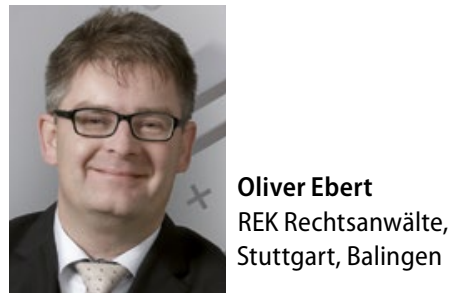

besondere $₫ 128$ SGB V), auch bislang schon problematisch. Die Einhaltung dieser Vorschriften wurde jedoch von der ärztlichen Selbstverwaltung bzw. den Krankenkassen nicht wirklich konsequent durchgesetzt, was letztlich wohl auch ein Grund für die Pönalisierung durch den Gesetzgeber war.

Es bleibt nun zu hoffen, dass die neuen Regelungen mit Augenmaß umgesetzt werden und die Staatsanwaltschaften keinen überzogenen Verfolgungseifer zeigen. Natürlich darf ein Arzt keinen Vorteil davon haben, dass er bestimmte Anbieter bei seiner Verordnung bevorzugt. Umgekehrt sollte man aber auch die Kirche im Dorf lassen, damit Ärzte sich nicht von übertriebenen Ängsten leiten lassen - denn was bislang zulässig war, wird auch jetzt nicht mit Strafe bedroht.

- Der Autor ist Rechtsanwalt und Digital Health Consultant Beider Deutschen Diabetes-Gesellschaft (DDG) ist er Vorsitzender des Ausschuss Soziales und Mitglied im Beirat der AG Diabetes \& Technologie.

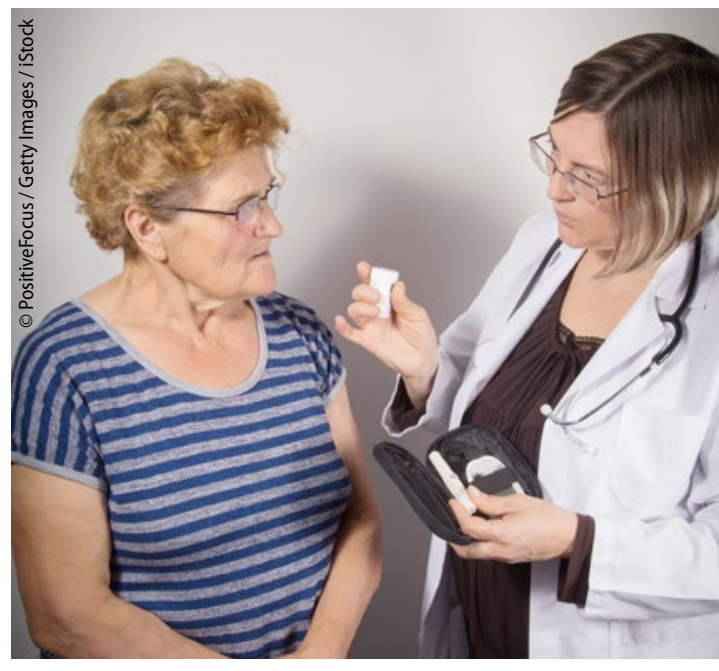

Dieses Messgerät kann die Patientin leider nicht mit nach Hause nehmen. 